\title{
A Systematic Review of Cultural Preferences for Receiving Medical “Bad News” in the United States
}

\author{
Christine Larkin, H. Russell Searight \\ Lake Superior State University, Sault Sainte Marie, USA \\ Email: hsearight@lssu.edu
}

Received 3 July 2014; revised 20 August 2014; accepted 4 September 2014

Copyright (C) 2014 by authors and Scientific Research Publishing Inc.

This work is licensed under the Creative Commons Attribution International License (CC BY). http://creativecommons.org/licenses/by/4.0/

\section{(c) (7) Open Access}

\begin{abstract}
According to the dominant models of medical ethics in the United States and many Western countries, physician disclosure of information such as diagnosis, treatment options, and prognosis is considered an essential precondition for patient informed consent. While being consistent with the principle of patient autonomy stressed in many Western healthcare systems, full disclosureparticularly of life-threatening diagnoses and poor prognoses-is inconsistent with the cultural values of many ethnic communities within the United States. A systematic review of research examining cultural preferences for disclosure of medical "bad news" was conducted. Results suggested that cultural preferences are more heterogeneous than has often been portrayed. Particularly when communicating with patients and families from culturally and ethnically diverse backgrounds, health care professionals should ask about preferences for receiving medical information and making treatment decisions.
\end{abstract}

\section{Keywords}

Medical Ethics, Health Care Communication, Cross Cultural Health

\section{Introduction}

Technological and medical advances have led to a dramatic rise in life expectancy. Between 1980 and 2003 , the average male life expectancy at birth increased by 4.8 years and the average female life expectancy increased by 2.7 years [1]. It was hypothesized that this increase in life expectancy would be accompanied by a decrease in the length of the morbid life [2]. However, this prediction has often been shown to be untrue. Instead, more patients are facing a gradual decline in health rather than sudden death [3]. In addition, medical technology has 
advanced to the point at which individual life may be prolonged—even in the face of terminal illness. These medical realities have led to increased attention to the ethical and legal aspects of end-of-life care.

In the United States, both law and the prevailing models of medical ethics stress individualism and autonomy. In terms of patients making decisions about their own medical treatment, true autonomy is predicated on being fully informed about one's medical condition, its probable course, and treatment options. To this end, the United States healthcare system has developed a policy of full disclosure, even in cases of serious illness or "bad news". "Bad news" is traditionally defined as any news that drastically and negatively alters the patient's view of the future" [4]. In the U.S., this norm of medical disclosure is a relatively recent phenomenon. In 1961, 90\% of physicians surveyed indicated that they would not disclose a cancer diagnosis to a patient. In 1979, there was almost a complete reversal with $97 \%$ of physicians indicating that they would inform a patient of a cancer diagnosis [5] [6].

This policy of disclosure was legally institutionalized with the Patient Self-Determination Act (PSDA) of 1991. This act requires all medical institutions receiving Medicare or Medicaid funds to provide written information to patients about their right to accept or refuse treatment and to encourage the use of advance directives. However, relatively soon after its implementation, the disclosures mandated by the PSDA became a source of conflict among some cultural and ethnic communities in the United States.

Individual self-reliance and independence are key values that undergird ethics and law in the United States. In medical settings, this orientation supports full disclosure of medical information since disclosure is believed to optimize a patient's ability to make autonomous choices. However, in many cultures, such as many Native American and Asian communities, a collectivist orientation governs decision-making about important life issues. In these communities, individuals are embedded in an interdependent family and community. From a collectivist perspective, insistence on advance directives, full medical disclosure to a patient, or requiring patient-based decision making may be culturally inappropriate or even harmful [7].

Outside of the U.S., relevant information about one's medical condition and treatment options is often deliberately withheld from seriously or terminally ill patients. Instead, a physician will often conceal "bad news" with nonspecific terminology such as "a growth" when discussing cancer with a patient. However, in these societies in which patients do not directly receive medical information, it is often common for the physician to reveal the full details to the family. This pattern of information sharing is based on a variety of cultural beliefs including (1) discussing serious illness and death is impolite and disrespectful; (2) open discussion of serious illness may cause depression or anxiety for the patient; (3) direct disclosure may eliminate hope; (4) verbalizing an illness makes the condition more real due to the power of the spoken word [8].

In ethnic cultures which shield patients from medical "bad news", the U.S. system of direct full disclosure may be seen, at minimum as disrespectful, but also may be viewed as cruel and as contributing to further harm to the patient. A classic study of ethnicity and medical bad news was conducted by Blackhall and colleagues [9] who found that Korean- and Hispanic-American were less likely to indicate that a patient should be informed of their diagnosis. In addition, members of these ethnic groups also stated a distinct preference for family-centered rather than patient-centered decision-making. Since the publication of these findings nearly 20 years ago, there have been a series of studies examining cross-cultural preferences for medical decision-making. However, the existing literature has provided few consistent guidelines for health care providers about communication with patients and their families.

\section{Current Study}

A systematic review is "the application of scientific strategies that limit bias by the systematic assembly, critical appraisal and synthesis of all relevant studies on a specific topic" [10]. A systematic review can be used to answer a clearly formatted clinical question by following a standardized format for surveying and organizing the literature on a specific topic. Systematic reviews have gained popularity as evidence-based medicine has grown in practice [10]-[13].

The objective of this project was to perform a systematic review of research examining cultural preferences for disclosure of medical "bad news". The specific question which was examined was whether there were clear patterns of differences between cultural and ethnic minority groups in the United States regarding preferences for disclosure of medical "bad news". 


\section{Methods}

\subsection{Search Strategy}

The National Center for Biotechnology Information was searched through the PUBMED online database using the search terms found in Figure 1. In addition, an ancestry search of the reference lists of retrieved articles was performed. Google Scholar was also used to locate articles using the retrieved articles as a reference.

\subsection{Inclusion Criteria}

To be selected, the article must have been a systematic quantitative or qualitative study involving at least one cultural or ethnic minority group in the United States. In addition, these research reports must have specifically addressed the topic of disclosing or receiving medical "bad news" about a life-threatening condition. Studies were only included if they specifically dealt with both disclosure of bad news and minority groups in the United States. Therefore, studies dealing with other end-of-life care issues such as advance directives or studies dealing with the disclosure of bad news in the general United States population did not meet inclusion criteria. No specific time frame for article publication was specified. Only primary source articles were included. Only articles that were published in English were included. Articles that dealt specifically with children or articles that were based on populations outside of the United States were excluded. For example, a study within a neonatal unit would be excluded as would a study that took place in the United Kingdom.

\subsection{Screening and Data Extraction}

Articles were managed in Excel. Titles and abstracts were initially assessed to eliminate those not related to the specified topic. Studies that were eliminated included cross-national studies, generalized end-of-life care reviews, studies that lacked primary data, and studies that dealt only with other end-of-life topics. The articles that met inclusion criteria were then read in full. If upon review, an article no longer appeared to meet inclusion criteria, the reason was noted and the article was not included in the review. The majority of disregarded articles were cross-national studies that compared disclosure preferences of the general U.S. population with the general population of another country. If after this analysis an article was still found to have met inclusion criteria, the data were extracted and included in the review.

\subsection{Quality of Studies-Strength of Recommendation Taxonomy (SORT)}

The quality of the studies included in this review was assessed using the Strength of Recommendations Taxonomy developed by the U.S. family medicine and primary care journals [14]. This system includes ratings of A, $\mathrm{B}$, or $\mathrm{C}$ for the strength of recommendation for a body of evidence. A chart summarizing these levels and the types of retrieved articles that were included in these levels is found in Figure 2.

\subsection{Reporting Results and Data Analysis}

Results were analyzed qualitatively to summarize findings and quantitatively through a "box score" analysis. An included article was summarized and then assessed to determine if the ethnic minority sampled indicated a

“United States” OR “U.S.” OR “American”

AND

“palliative” OR "terminal” OR "end of life” OR "cancer” OR “death” OR “dying” OR “continued care” OR "advance directive” OR "hospice” OR "supportive care”

AND

“ethnic" or "intercultural” OR “cross-cultural” OR "transcultural” OR "culture" OR “migrant” OR “minority” OR "diversity”

AND

“bad news” OR "truth telling” OR "prognosis” OR “communication” OR “disclosing” 


\begin{tabular}{|c|c|c|}
\hline $\begin{array}{c}\text { Strength of } \\
\text { Recommendation }\end{array}$ & Definition & $\begin{array}{l}\text { Types of Retrieved Articles } \\
\text { that Met the Definition }\end{array}$ \\
\hline A & $\begin{array}{l}\text { Recommendation based on consistent and } \\
\text { good quality patient oriented evidence. }\end{array}$ & $\begin{array}{l}\text { Multiple studies involving random } \\
\text { assignment; systematic reviews; meta-analyses }\end{array}$ \\
\hline B & $\begin{array}{l}\text { Recommendation based on inconsistent or } \\
\text { limited-quality patient oriented evidence }\end{array}$ & $\begin{array}{l}\text { Limited number of quantitative studies } \\
\text { with differing methodological rigor; } \\
\text { trends across studies but with some } \\
\text { contradictory findings; multiple systematic } \\
\text { qualitative studies with consistent findings }\end{array}$ \\
\hline $\mathrm{C}$ & $\begin{array}{l}\text { Recommendations based on consensus, } \\
\text { usual practice, opinion, disease-oriented evidence, } \\
\text { or case series for studies of diagnosis, } \\
\text { treatment, prevention, or screening }\end{array}$ & $\begin{array}{l}\text { Case reports; opinion, limited number } \\
\text { of small sample quantitative studies; } \\
\text { limited number of qualitative reports }\end{array}$ \\
\hline
\end{tabular}

Figure 2. Strength of recommendation taxonomy (from [14]).

disclosure preference other than a direct description of their condition and/or its possible course. Possible results included (1) yes, (2) no, (3) no consensus, (4) not directly addressed.

Studies that did not directly address the question were not used in the quantitative box score analysis. The studies that did directly address the question were then used to generate the percentages of studies that did indicate a difference in disclosure preference, did not indicate a difference in disclosure preference, or did not reach a single consensus on disclosure preference.

\section{Results}

The search terms indicated in Figure 1 were utilized systematically via a permutation methodology. A total of 1200 individual searches were performed and 5964 articles were returned. Of these results, only 30 published reports met the search criteria after initial screening of the title and abstract [9] [15]-[43]. Of the initial total, 5934 articles were disregarded. The full text of these 30 articles was then examined and upon closer examination, 15 published reports were found not to meet the search criteria. Four published reports were found to be crossnational studies that compared the preferences about disclosure of "bad news" in the general U.S. population to the general population of a foreign nation. Four reports dealt with another end-of-life care topic - often family communication about "bad news". Two articles were found to be reviews about minority ethnicities in endof-life care. Four were found to deal with the topic of cultural preferences about disclosure of bad news in endof-life care in the U.S., but did not include any data collection. These were mainly case studies or reports of personal experiences with the topic. Because group data were not collected and also because of the limited number of these reports, it was determined that, collectively, they did not qualify as level "B" or possibly even level "C" in terms of quality. Studies that were not at least of level "B" in terms of quality were eliminated from the final analysis. A total of 16 studies met inclusion criteria and were included in the review. These 16 studies were then further divided into seven quantitative and nine qualitative studies. The breakdown of the search results is summarized in Figures 3-5.

The studies were further divided by ethnicity and subject population. Ethnicities represented included: African American, Hispanic American, Korean American, Japanese American, Bosnian American, Indo-Caribbean Hindu American, and Russian American. Some studies did not differentiate between ethnicities and these study population will be referred to as "Minority Americans." Subject populations included elderly individuals, patients, healthcare providers, caregivers, or the general minority population. The number of studies that dealt with each ethnicity and the types of subject populations included in these studies is summarized in Figure 4 for the quantitative studies and in Figure 5 for the qualitative studies. Studies that examined more than one ethnic group are counted for both ethnicities. Table 1 provides a summary of the qualitative studies and Table 2 provides a summary of qualitative studies, including author, year published, journal, SORT level, subject population, sample size, methods utilized, and relevant results.

A box score analysis was performed to examine the frequency of preferences regarding medical bad news by ethnic or cultural groups. When examining the studies as a complete group (See Table 3), it appears that in the majority of studies (61\%), members of non-Northern European ethnic communities expressed a preference for full disclosure of medical information to patients. However, in approximately one third of the studies (31\%), a preference for non-disclosure was indicated by members of minority cultures. One study (8\%) found that there 


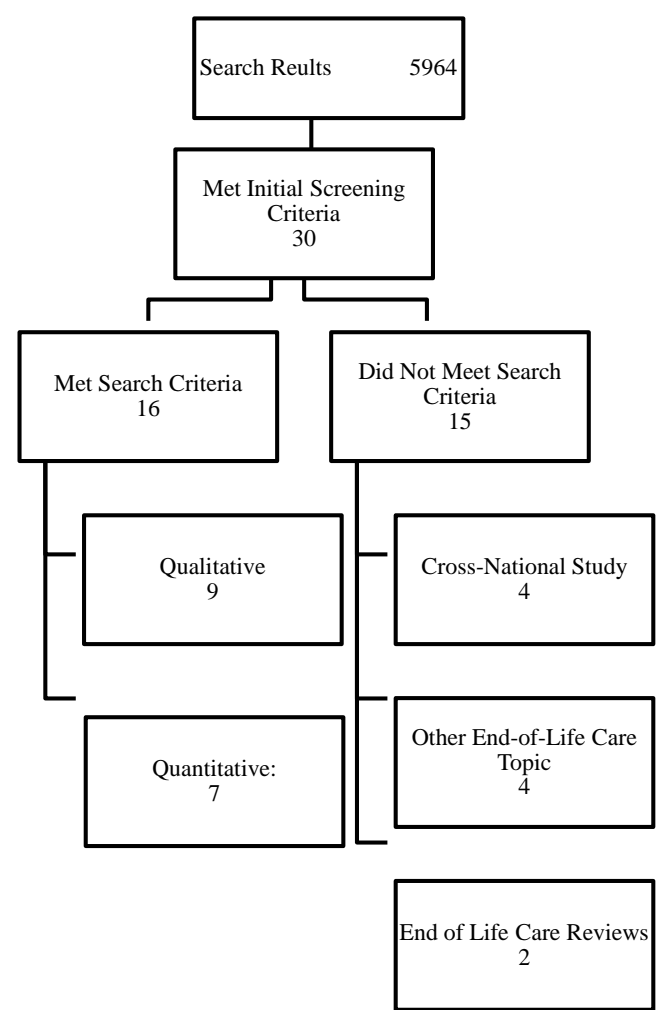

Figure 3. Summary of search results.

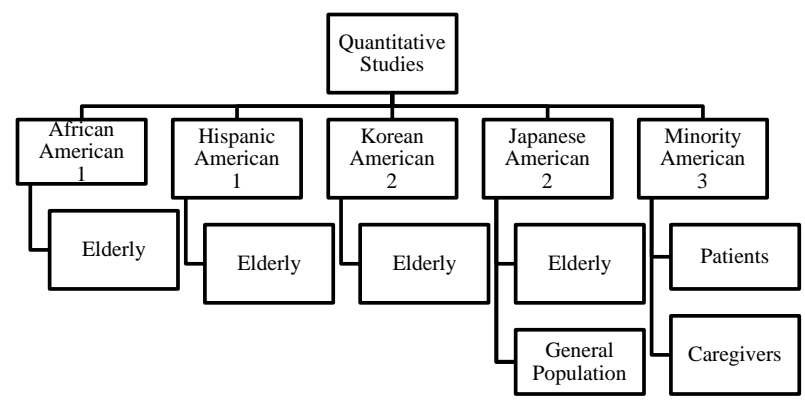

Figure 4. Distribution of ethnicity and subject population in quantitative studies.

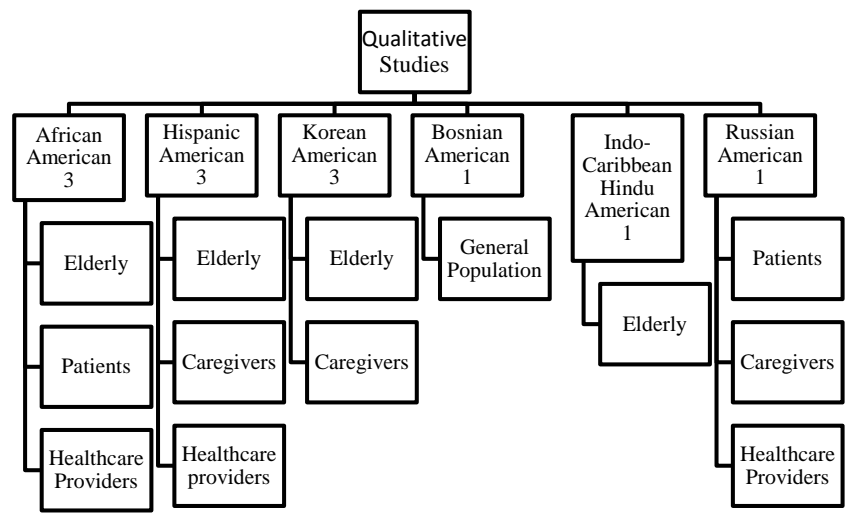

Figure 5. Distribution of ethnicity and subject population in qualitative studies. 
Table 1. A list and summary of relevant data from the six quantitative studies.

\begin{tabular}{|c|c|c|c|c|c|c|}
\hline Author & Year & Journal & SORT & Subject Population & $\mathbf{N}$ & Method \\
\hline \multicolumn{7}{|c|}{1} \\
\hline $\begin{array}{l}\text { Blackhall, L.J. } \\
\text { Murphy, S.T. } \\
\text { Frank, G. } \\
\text { Michel, V. } \\
\text { Azen, S. }\end{array}$ & 1995 & $J A M A$ & A & Elderly Population & $\begin{array}{l}200 \text { European Americans; } \\
200 \text { African Americans; } 200 \text { Korean } \\
\text { Americans; } 200 \text { Mexican Americans }\end{array}$ & Survey \\
\hline
\end{tabular}

Results

Korean Americans (47\%) and Mexican Americans (65\%) were significantly less likely to believe that a patient should be told the diagnosis of metastatic cancer than European Americans (87\%) and African Americans. Korean Americans (35\%) and Mexican Americans (48\%) were significantly less likely to believe that a patient should be told about a terminal prognosis than European Americans (69\%) and African Americans (63\%).

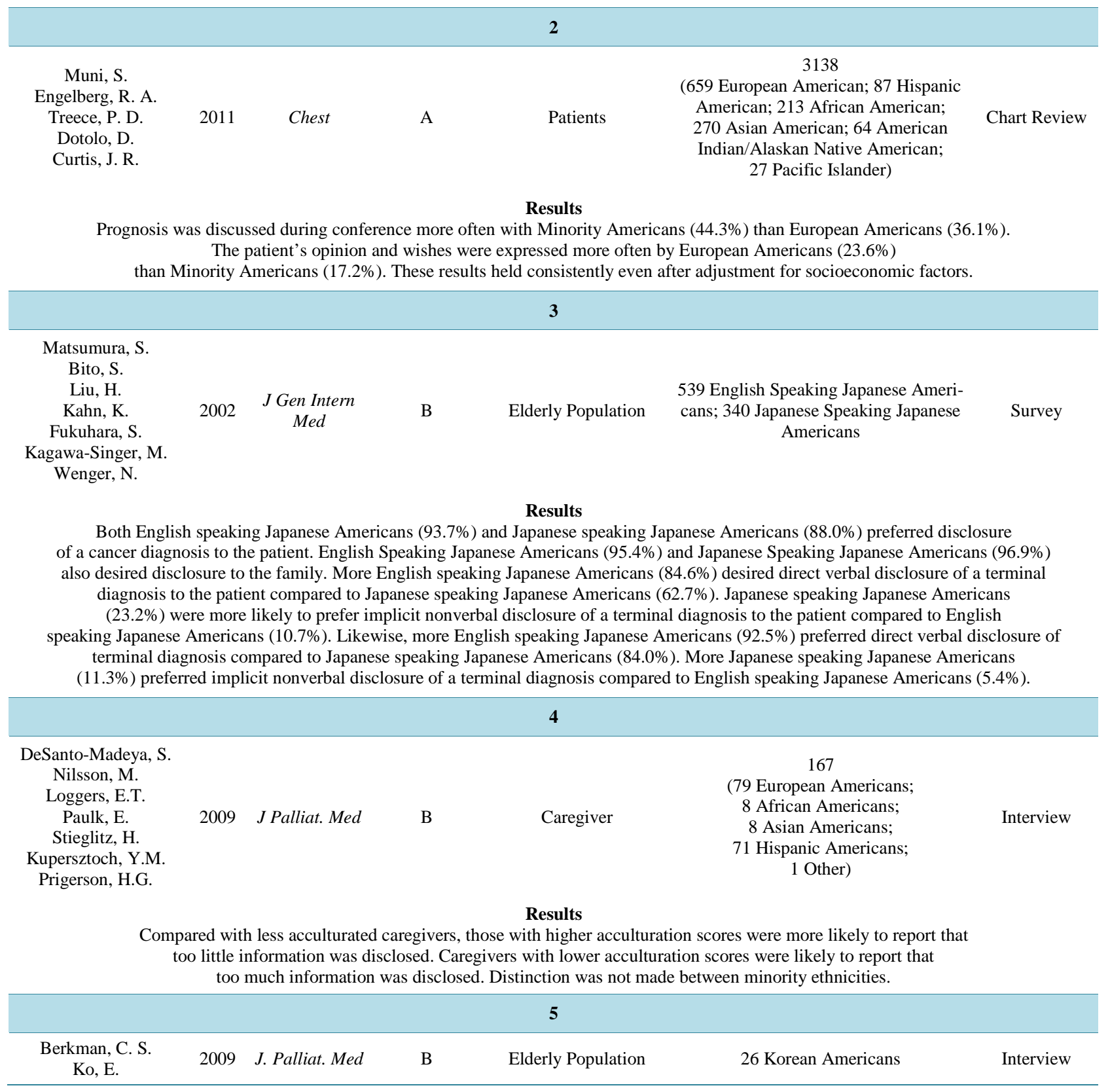




\section{Continued}

\section{Results}

Most of the Korean Americans interviewed wanted their doctor to tell them if they had cancer (88\%) or if they would probably die of cancer (85\%). Most Korean Americans also disagreed with the view that a doctor should avoid discuss death and dying because it could be upsetting to the patient (65\%).

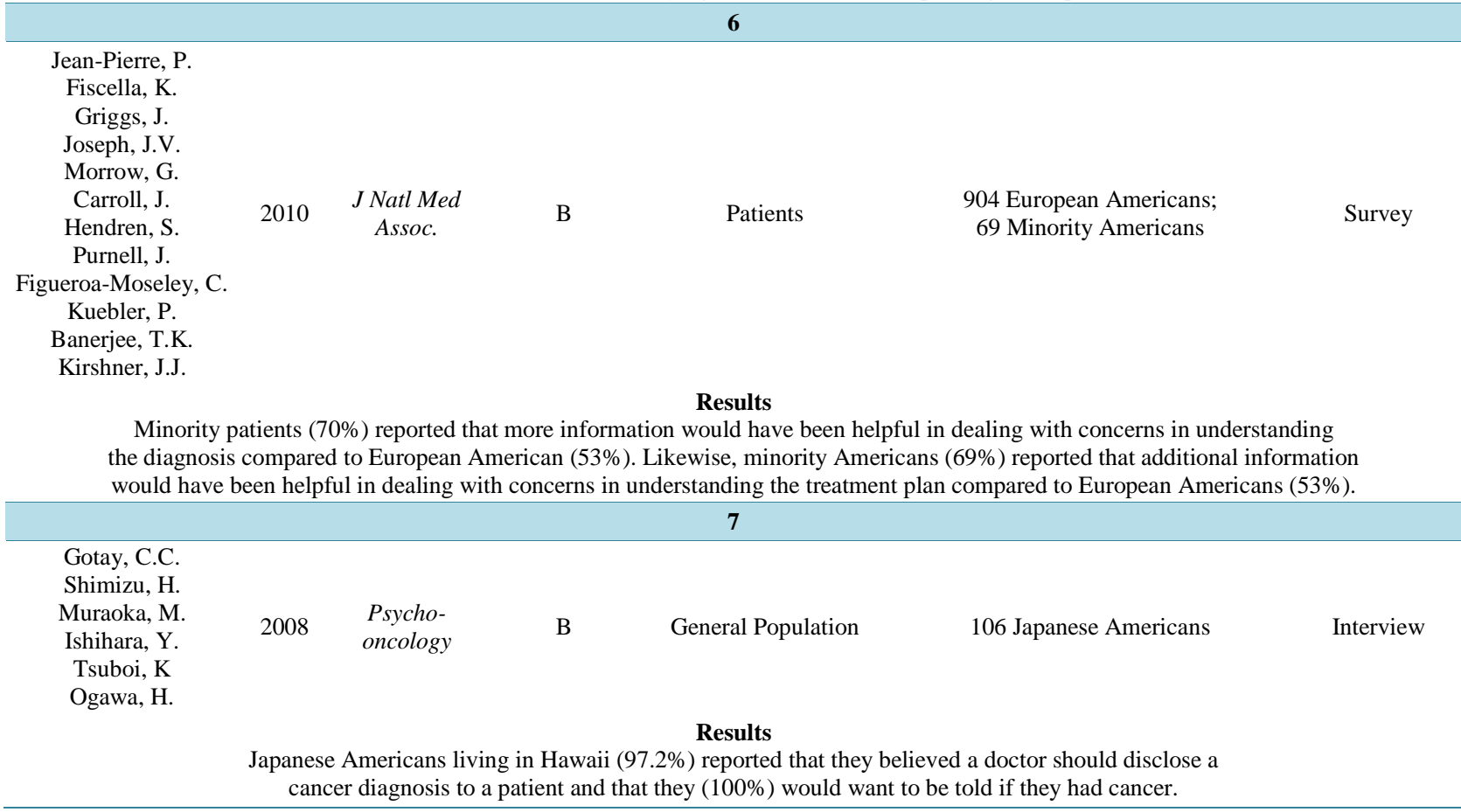

\section{Table 2. A list and summary of relevant data from the nine qualitative studies.}

\begin{tabular}{|c|c|c|c|c|c|c|}
\hline Author & Year & Journal & SORT & Subject Population & $\mathbf{N}$ & Method \\
\hline \multicolumn{7}{|c|}{1} \\
\hline Kwak, J. Salmon, J.R. & 2007 & J Am Geriatric Soc. & B & $\begin{array}{l}\text { Elderly Population; } \\
\text { Caregivers }\end{array}$ & $\begin{array}{l}20 \text { Elderly Korean } \\
\text { Americans; } \\
16 \text { Caregivers }\end{array}$ & Focus Groups \\
\hline
\end{tabular}

The sampled elderly Korean Americans had little knowledge about advanced directives, but once described saw them as useful in guiding adult children in EOL care decisions. Elderly Korean Americans demonstrated a preference for indirect and nonverbal communication referred to as "noon-chi”. Both elderly Korean Americans and Korean American caregivers acknowledged the role a physician plays in end-of-life decisions and treatment. Caregivers supported physician initiated conversations about end-of-life care. Korean American preference for indirect "noon-chi" communication of bad news was indicated to be primarily relevant within the family setting. Korean Americans indicated that direct communication about end-of-life decisions was appropriate when initiated by a physician.

\section{2}

Braun, U.K.

Ford, M.E.

Beyth, R.J.

McCullough, L.B.

\section{Results}

Hispanic American physicians noted culturally-based differences about truth-telling and stated that Hispanic American families often seek to conceal bad news from a very sick patient to protect them. African American and European American physicians also noted ethnic differences regarding truth-telling, but indicated that these differences occurred primarily with Hispanic American, Asian American, or Middle Eastern patients.

\section{3}

Blackhall, L.J.

Frank, G.

Murphy, S.

Michel, V.
20 European

Americans; 20

African Americans;

20 Korean

Americans; 20

Mexican Americans 


\section{Continued}

\section{Results}

European Americans and African Americans supported truth-telling because they felt it allowed them to maintain personal control of decisions, treatment, and the dying process. They viewed truth-telling as empowering. African Americans believed truth-telling was required to properly seek spiritual guidance and influence. All ethnicities believed that a patient intuitively knows they are very sick.

European Americans and African Americans used this to support truth-telling because the patient already is aware of the situation.

Mexican Americans and Korean Americans believed this was a reason to avoid explicit disclosure of "bad news". They viewed

direct disclosure and discussion of "bad news" as cruel and potentially harmful to the patient. Rather, they wanted to protect the patient from pain. However, Korean Americans and Mexican Americans supported truth-telling provided that it did not take away the patient's hope, which was viewed as being cruel and harmful. European Americans and African Americans acknowledged that truth

can be harmful to some people, but not to most people. Korean Americans linked the issue of truth-telling with "hydo" and

"noon-chi"—filial piety and implicit communication. Specifically, Korean Americans felt that family members had a familial duty to protect the patient from cruel/harmful details, while still communicating the severity of the situation indirectly.

\begin{tabular}{|c|c|c|c|c|c|c|}
\hline & & & 4 & & & \\
\hline $\begin{array}{l}\text { Kreling, B. } \\
\text { Selsky, C. } \\
\text { Perret-Gentil, M. } \\
\text { Huerta, E.E. }\end{array}$ & 2010 & Palliat Med & B & Caregiver & $\begin{array}{c}15 \text { Hispanic } \\
\text { Americans; } \\
15 \text { European } \\
\text { Americans }\end{array}$ & $\begin{array}{l}\text { Focus Group; } \\
\text { Interview }\end{array}$ \\
\hline
\end{tabular}

Results

Hispanic American caregivers reported denial, preference for less information, and maintaining secrecy abut prognosis, even after enrollment in hospice. Most Hispanic American caregivers were surprised and disturbed by the open communication in hospice. Hispanic American caregivers felt that truth-telling was harmful and that it was the caregiver's responsibility to protect patients from knowledge of their illness, deny imminent death, and act as if the patient was getting well.

\begin{tabular}{|c|c|c|c|c|c|c|}
\hline \multicolumn{7}{|c|}{5} \\
\hline Searight, H.R. Gafford, J. & 2005 & J Immigr Health & B & General Population & 12 Bosnian Americans & Focus Group \\
\hline
\end{tabular}

Approximately half the Bosnian Americans expressed a desire to know about serious illness, primarily for practical reasons. The remaining group indicated that they would not want to know about a serious illness, especially if it was terminal. The reason for non-disclosure was the belief that it would generate negative feelings and be burdensome to the family. This group viewed direct disclosure as insensitive.

\begin{tabular}{cccccc}
\hline & 6 & & \\
\hline $\begin{array}{c}\text { Berkman, C.S. } \\
\text { Ko, E. }\end{array}$ & $2010 \quad J$ PsychosocOncol & B $\quad$ Elderly Population & 23 Korean Americans $\quad$ Focus Group
\end{tabular}

This study qualitatively explains the results generated in the quantitative study included above by the same authors.

The Korean Americans who desired disclosure felt it allowed patients to make decisions and preparations.

Those who did not prefer disclosure felt that it could cause negative feelings, be erroneous, or hasten death

if not told in a positive manner. Korean Americans also felt that "bad news" would be less traumatic

for elderly patients because they have lived longer and serious health problems were more likely to be expected.

\begin{tabular}{|c|c|c|c|c|c|c|}
\hline \multicolumn{7}{|c|}{7} \\
\hline $\begin{array}{l}\text { Rao, A.S., Desphande, O.M., } \\
\text { Jamoona, C. } \\
\text { Reid, C.M. }\end{array}$ & 2008 & J Am Geriatric Soc. & B & Elderly Population & $\begin{array}{l}44 \text { Indo-Caribbean } \\
\text { Hindu Americans }\end{array}$ & Interview \\
\hline
\end{tabular}

Indo-Caribbean Hindu Americans tended to agree that diagnoses should be disclosed to patients and their families, even if that meant disclosing the possibility of death.

$\begin{array}{ccccc} & \mathbf{8} & & \text { Healthcare Providers; } \\ \text { Dohan, D., Levintova, M. } & 2007 \quad \text { J Gen Intern Med } & \text { B } & \begin{array}{c}\text { Caregivers; and } \\ \text { Patients }\end{array} & \begin{array}{c}\text { Focus Groups; } \\ \text { Interviews; } \\ \text { Observation }\end{array}\end{array}$

Many Russian Americans view a cancer diagnosis as a "death sentence”. Thus, disclosure can cause depression, hopelessness, and decrease the will to live. Many providers will avoid using the word, "cancer" and instead substitute with a code word such as "tumor". Many providers noted that the patient was often open to full disclosure, but the family was against informing the patient. It was likely to anger family members if the patient was directly informed of "bad news". Russian Americans seem to prefer disguised, implied disclosure.

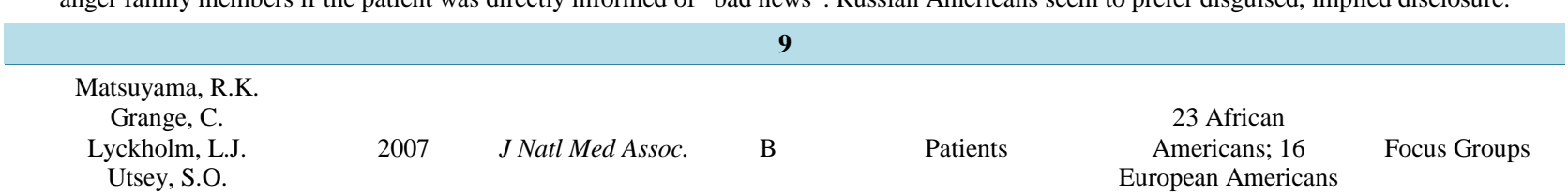

Very few African Americans indicated that they would want to know little or nothing about their cancer. The majority wanted their healthcare provider to keep them informed. 
Table 3. Box score analysis of disclosure preferences.

\begin{tabular}{|c|c|c|c|c|}
\hline \multirow{2}{*}{ Study } & \multicolumn{4}{|c|}{ Ethnic Minority Disclosure Preference Differs from Western Principle of Full Disclosure } \\
\hline & Yes & No & No Consensus & Not Directly Addressed \\
\hline Blackhall et al. 1995 [9] & $\mathrm{X}$ & & & \\
\hline Muni et al. 2011 [21] & & & & $\mathrm{X}$ \\
\hline Matsumura et al. 2002 [25] & $\mathrm{X}$ & & & \\
\hline DeSanto-Madeya et al.2009 [29] & & $\mathrm{X}$ & & \\
\hline Berkman and Ko 2009 [33] & & $\mathrm{X}$ & & \\
\hline Jean-Pierre 2010 [36] & & $\mathrm{X}$ & & \\
\hline Kwak and Salmon 2007 [15] & & $\mathrm{X}$ & & \\
\hline Braun et al. 2010 [22] & $\mathrm{X}$ & & & \\
\hline Blackhall et al. 2001 [20] & & & & $\mathrm{X}$ \\
\hline Kreling et al. 2010 [27] & $\mathrm{X}$ & & & \\
\hline Searight and Gafford 2005 [31] & & & $\mathrm{X}$ & \\
\hline Berkman and Ko 2010 [38] & & & & $\mathrm{X}$ \\
\hline Rao et al. 2008 [39] & & $\mathrm{X}$ & & \\
\hline Dohan and Levintova 2007 [41] & & $\mathrm{X}$ & & \\
\hline Matsuyama et al. 2007 [42] & & $\mathrm{X}$ & & \\
\hline Gotay et al 2008 [40] & & $\mathrm{X}$ & & \\
\hline Total & 4 & 8 & 1 & 3 \\
\hline Percentage & $31 \%$ & $61 \%$ & $8 \%$ & N/A \\
\hline
\end{tabular}

was no consensus about disclosure preference. Three studies did not directly address the topic in a yes or no fashion. These articles were excluded from analysis.

\section{Discussion}

Studies addressing "bad news" disclosure preferences among African American, Hispanic American, Korean American, Japanese American, Bosnian American, Indo-Caribbean American, and Russian American ethnic populations were identified. These studies included a variety of sample populations including elderly individuals, patients, healthcare providers, and the general population. It was indicated that, in general, "bad news" disclosure preferences of African Americans do not differ from those of persons of White Western European background. However, among U.S. residents of Hispanic American, Asian American, and Eastern European background, there were suggestions of slight to moderate differences in disclosure preferences compared with these other two ethnic groups.

This review, rather than confirming that minority ethnicities have different disclosure preferences from the majority of European Americans, demonstrates only that there is greater variability in the disclosure preferences of Hispanic American, Asian American, and Eastern European Americans than within the dominant Western European American population. This review suggests that the majority of Americans who are members of cultural or ethnic minorities prefer direct disclosure of information such as diagnosis, treatment options, and prognosis. When examined in isolation from other ethnicities studied, Hispanic Americans, Asian Americans, and Eastern European Americans were somewhat more likely to indicate a preference for non-disclosure, non-verbal implied disclosure, or disguised disclosure. This variation is, however, greater among these ethnic groups than the general United States population and when viewed as a group, more minority Americans do prefer nondisclosure 
compared with individuals of White, Western European background.

The disclosure preference of Hispanic Americans, Asian Americans, and Eastern European Americans also appears to be different from that of Hispanic, Asian, and Eastern European nationals who currently reside outside of the United States. Two of the studies included in this review contained quantitative data directly comparing minority American disclosure preferences with Japanese citizens residing in their home country. Both studies found a significantly higher percentage of Japanese Americans preferred disclosure over their nonimmigrant Japanese counterparts [28] [43]. Likewise, the preference for nondisclosure in Latin American, Asian, and Eastern European countries appears to be much higher than among Americans of the same ethnicity [37]. It appears that disclosure preferences of minority Americans seem to lie between that of the general U.S. population and the population of their country of origin. This pattern suggests that acculturation significantly influences beliefs regarding "truth telling". Further study with a specific focus on differences in disclosure preference among minority Americans and individuals from their respective country-of-origin would be valuable in this regard for healthcare providers.

For health care providers, the findings of this review suggest that clinicians addressing end-of-life issues should be aware of the greater degree of variability in disclosure preference among contemporary Hispanic American, Asian American, and Eastern European populations as compared with Whites of Northern European background. Provider-patient relationships are the cornerstone of health care in the United States. Effective treatment is based upon an effective clinician-patient relationship in which the patient trusts the competence and judgment of the healthcare provider. This relationship is especially important in end-of-life care and should not be jeopardized by a lack of cultural understanding. It is important for the healthcare provider to realize that some Hispanic American, Asian American, Eastern European American, and even some Western European and African American patients may not want full and direct disclosure. Ignoring cultural and individual patient variability regarding disclosure or applying cultural stereotypes indiscriminately across all patients can lead to conflict and tension during end-of-life care. The most efficient way to prevent these disclosure issues and consequent conflict is to offer the patient the choice of non-disclosure. As suggested by Searight and Gafford [8], the healthcare provider can describe the dimensions of informed consent and offer to provide information regarding diagnosis, treatment options, and prognosis. A patient can then make a personal choice for disclosure or nondisclosure. Should an individual patient prefer nondisclosure, the healthcare provider should be clear that the information will always be available to them if they wish to change their mind. This approach respects both the U.S. healthcare system's legal and ethical principles of autonomy and informed consent while recognizing preferences for nondisclosure [8] [44].

This review has several limitations. The most significant limitation is the restricted number of studies, especially quantitative investigations that included a reasonable sample size. Only two studies included in this review had sample populations large enough to qualify as SORT level A studies. Furthermore, none of the studies included met the criterion of random selection from a larger population. This calls into question whether the results of this review are representative of all minorities or only those that were conveniently sampled-typically these samples were drawn from or near a teaching hospital. The majority of the sampled minority American populations were also elderly and studies have shown that attitudes towards end-of-life care may change as an individual ages [44].

\section{References}

[1] National Center for Health Statistics (2007) Health, United States 2007: With Chartbook on Trends in the Health of Americans. Dept. of Health and Human Services, Centers for Disease Control and Prevention, National Center for Health Statistics, Hyattsville.

[2] Fries, J.F. (1980) Aging, Natural Death, and the Compression of Morbidity. The New England Journal of Medicine, 303, 130-135. Print. http://dx.doi.org/10.1056/NEJM198007173030304

[3] Crimmins, E.M. and Beltrán-Sánchez, H. (2010) Mortality and Morbidity Trends: Is There Compression of Morbidity? The Journals of Gerontology, 66B, 75-86. http://dx.doi.org/10.1093/geronb/gbq088

[4] Buckman, R. (1992) How to Break Bad News: A Guide for Health Professionals. Johns Hopkins Press, Baltimore.

[5] Novack, D.H., Plumer, R., Smith, R.L., Ochitill, H., Morrow, G.R. and Bennett, J.M. (1979) Changes in Physicians' Attitudes toward Telling the Cancer Patient. Journal of the American Medical Association, 241, 897-900. http://dx.doi.org/10.1001/jama.1979.03290350017012

[6] Oken, D. (1961) What to Tell Cancer Patients: A Study of Medical Attitudes. Journal of the American Medical Associ- 
ation, 175, 1120-1128. http://dx.doi.org/10.1001/jama.1961.03040130004002

[7] Candib, L.M. (2002) Truth Telling and Advance Planning at the End of Life: Problems with Autonomy in a Multicultural World. Families, Systems, \& Health, 20, 213-228. http://dx.doi.org/10.1037/h0089471

[8] Searight, H.R. and Gafford, J. (2005) Cultural Diversity at the End of Life: Issues and Guidelines. American Family Physician, 71, 515-522.

[9] Blackhall, L.J., Murphy, S.T., Frank, G., Michel, V. and Azen, S. (1995) Ethnicity and Attitudes toward Patient Autonomy. Journal of the American Medical Association, 274, 820-825. http://dx.doi.org/10.1001/jama.1995.03530100060035

[10] Wright, R.W., Brand, R.A., Dunn, W. and Spindler, K.P. (2007) How to Write a Systematic Review. Clinical Orthopaedics and Related Research, 455, 23-29. http://dx.doi.org/10.1097/BLO.0b013e31802c9098

[11] Cook, D.J., Sackett, D.L. and Spitzer, W.O. (1995) Methodologic Guidelines for Systematic Reviews of Randomized Control Trials in Health Care from the Potsdam Consultation on Meta-Analysis. Journal of Clinical Epidemiology, 48, 167-171.

[12] Sackett, D.L., Rosenberg, W.M., Gray, J.A., Haynes, R.B. and Richardson, W.S. (1996) Evidence Based Medicine: What It Is and What It Isn't. BMJ: British Medical Journal, 312, 71-72.

[13] Davidoff, F., Haynes, B., Sackett, D. and Smith, R. (1995) Evidence Based Medicine. BMJ: British Medical Journal, 310, 1085-1086.

[14] Ebell, M.H., Siwek, J., Weiss, B.D., Woolf, S.H., Susman, J., Ewigman, B. and Bowman, M. (2004) Strength of Recommendation Taxonomy (SORT): A Patient-Centered Approach to Grading Evidence in the Medical Literature. The Journal of the American Board of Family Practice, 17, 59-67. http://dx.doi.org/10.3122/jabfm.17.1.59

[15] Kwak, J. and Salmon, J.R. (2007) Attitudes and Preferences of Korean-American Older Adults and Caregivers on End-of-Life Care. Journal of the American Geriatrics Society, 55, 1867-1872. http://dx.doi.org/10.1111/j.1532-5415.2007.01394.x

[16] Csikos, A., Mastrojohn, J., Albanese, T., Richmond, M.J., Radwany, S. and Busa, C. (2010) Physicians’ Beliefs and Attitudes about End-of-Life Care: A Comparison of Selected Regions in Hungary and the United States. Journal of Pain and Symptom Management, 39, 76-87. http://dx.doi.org/10.1016/j.jpainsymman.2009.05.019

[17] Gabbay, B.B., Matsumura, S., Etzioni, S., Asch, S.M., Rosenfeld, K.E., Shiojiri, T., Balingit, P.P. and Lorenz, K.A. (2005) Negotiating End-of-Life Decision Making: A Comparison of Japanese and US Residents' Approaches. Academic Medicine, 80, 617-621. http://dx.doi.org/10.1097/00001888-200507000-00003

[18] Voltz, R., Akabayashi, A., Reese, C., Ohi, G. and Sass, H.M. (1998) End-of-Life Decisions and Advance Directives in Palliative Care: A Cross-Cultural Survey of Patients and Health-Care Professionals. Journal of Pain and Symptom Management, 16, 153-162. http://dx.doi.org/10.1016/S0885-3924(98)00067-0

[19] Braun, U.K., Ford, M.E., Beyth, R.J. and McCullough, L.B. (2010) The Physician’s Professional Role in End-of-Life Decision-Making: Voices of Racially and Ethnically Diverse Physicians. Patient Education and Counseling, 80, 3-9. http://dx.doi.org/10.1016/j.pec.2009.10.018

[20] Blackhall, L.J., Frank, G., Murphy, S. and Michel, M.V. (2001) Bioethics in a Different Tongue: The Case of Truth-Telling. Journal of Urban Health, 78, 59-71. http://dx.doi.org/10.1093/jurban/78.1.59

[21] Muni, S., Engelberg, R.A., Treece, P.D., Dotolo, D. and Curtis, J.R. (2011) The Influence of Race/Ethnicity and Socioeconomic Status on End-of-Life Care in the ICU. Chest, 139, 1025-1033. http://dx.doi.org/10.1378/chest.10-3011

[22] Braun, U.K. and Beyth, R.J. (2008) Voices of African American, Caucasian and Hispanic Surrogates on the Burdens of End-of-Life Decision Making. Journal of General Internal Medicine, 23, 267-274. http://dx.doi.org/10.1007/s11606-007-0487-7

[23] Kwak, J. and Haley, W.E. (2005) Current Research Findings on End-of-Life Decision Making among Racially or Ethnically Diverse Groups. The Gerontologist, 45, 634-641. http://dx.doi.org/10.1093/geront/45.5.634

[24] Zager, B.S. and Yancy, M. (2011) A Call to Improve Practice Concerning Cultural Sensitivity in Advance Directives: A Review of the Literature. Worldviews on Evidence-Based Nursing, 8, 202-211. http://dx.doi.org/10.1111/j.1741-6787.2011.00222.x

[25] Matsumura, S., Bito, S., Liu, H., Kahn, K., Fukuhara, S., Kagawa-Singer, M. and Wenger, N. (2002) Acculturation of Attitudes Toward End-of-Life Care. Journal of General Internal Medicine, 17, 531-539. http://dx.doi.org/10.1046/j.1525-1497.2002.10734.x

[26] Beyene, Y. (1992) Medical Disclosure and Refugees. Telling Bad News to Ethiopian Patients. Western Journal of Medicine, 157, 328-332.

[27] Kreling, B., Selsky, C., Perret-Gentil, M., Huerta, E.E. and Mandelblatt, J.S. (2010) The Worst Thing about Hospice Is That They Talk about Death: Contrasting Hospice Decisions and Experience among Immigrant Central and South 
American Latinos with US-Born White, Non-Latino Cancer Caregivers. Palliative Medicine, 24, 427-434. http://dx.doi.org/10.1177/0269216310366605

[28] Shrank, W.H., Kutner, J.S., Richardson, T., Mularski, R.A., Fischer, S. and Kagawa-Singer, M. (2005) Focus Group Findings about the Influence of Culture on Communication Preferences in End-of-Life Care. Journal of General Internal Medicine, 20, 703-709. http://dx.doi.org/10.1111/j.1525-1497.2005.0151.X

[29] De Santo-Madeya, S., Nilsson, M., Loggers, E.T., Paulk, E., Stieglitz, H., Kupersztoch, Y.M. and Prigerson, H.G. (2009) Associations between United States Acculturation and the End-of-Life Experience of Caregivers of Patients with Advanced Cancer. Journal of Palliative Medicine, 12, 1143-1149. http://dx.doi.org/10.1089/jpm.2009.0063

[30] Andresen, J. (2001) Cultural Competence and Health Care: Japanese, Korean and Indian Patients in the United States. Journal of Cultural Diversity, 8, 109-121.

[31] Searight, H.R. and Gafford, J. (2005) It's Like Playing with Your Destiny: Bosnian Immigrants' Views of Advance Directives and End-of-Life Decision-Making. Journal of Immigrant Health, 7, 195-203. http://dx.doi.org/10.1007/s10903-005-3676-7

[32] Hepburn, K. and Reed, R. (1995) Ethical and Clinical Issues with Native-American Elders. End-of-life Decision Making. Clinics in Geriatric Medicine, 11, 97-111.

[33] Berkman, C.S. and Ko, E. (2009) Preferences for Disclosure of Information about Serious Illness among Older Korean American Immigrants in New York City. Journal of Palliative Medicine, 12, 351-357. http://dx.doi.org/10.1089/jpm.2008.0236

[34] Mitchell, J.L. (1998) Cross-Cultural Issues in the Disclosure of Cancer. Cancer Practice, 6, 153-160. http://dx.doi.org/10.1046/j.1523-5394.1998.006003153.x

[35] Zhang, A.Y., Zyzanski, S.J. and Siminoff, L.A. (2012) Ethnic Differences in the Caregiver's Attitudes and Preferences about the Treatment and Care of Advanced Lung Cancer Patients. Psycho-Oncology, 21, 1250-1253. http://dx.doi.org/10.1002/pon.2031

[36] Jean-Pierre, P., Fiscella, K., Griggs, J., Joseph, J.V., Morrow, G., Carroll, J., Hendren, S., Purnell, J., Figueroa-Moseley, C., Kuebler, P., Banerjee, T.K. and Kirshner, J.J. (2010) Race/Ethnicity-Based Concerns over Understanding Cancer Diagnosis and Treatment Plan. Journal of the National Medical Association, 102, 184-189.

[37] Surbone, A. (1993) The Information to the Cancer Patient: Psychosocial and Spiritual Implications. Supportive Care in Cancer, 1, 89-91. http://dx.doi.org/10.1007/BF00366901

[38] Berkman, C.S. and Ko, E. (2010) What and When Korean American Older Adults Want to Know about Serious Illness. Journal of Psychosocial Oncology, 28, 244-259. http://dx.doi.org/10.1080/07347331003689029

[39] Rao, A.S., Desphande, O.M., Jamoona, C. and Reid, C.M. (2008) Elderly Indo-Caribbean Hindus and End-of-Life Care: A Community-Based Exploratory Study. Journal of the American Geriatrics Society, 56, 1129-1133. http://dx.doi.org/10.1111/j.1532-5415.2008.01723.X

[40] Gotay, C.C., Shimizu, H., Muraoka, M., Ishihara, Y., Tsuboi, K. and Ogawa, H. (2004) Cancer-Related Attitudes: A Comparative Study in Japan and the US. Psycho-Oncology, 13, 665-672. http://dx.doi.org/10.1002/pon.792

[41] Dohan, D. and Levintova, M. (2007) Barriers beyond Words: Cancer, Culture and Translation in a Community of Russian Speakers. Journal of General Internal Medicine, 22, 300-305. http://dx.doi.org/10.1007/s11606-007-0325-y

[42] Matsuyama, R.K., Grange, C., Lyckholm, L.J., Utsey, S.O. and Smith, T.J. (2007) Cultural Perceptions in Cancer Care among African-American and Caucasian Patients. Journal of the National Medical Association, 99, 1113-1118.

[43] Duffy, S.A., Jackson, F.C., Schim, S.M., Ronis, D.L. and Fowler, K.E. (2006) Racial/Ethnic Preferences, Sex Preferences and Perceived Discrimination Related to End-of-Life Care. Journal of the American Geriatrics Society, 54, 150157. http://dx.doi.org/10.1111/j.1532-5415.2005.00526.x

[44] Braun, K., Pietsch, J.H. and Blanchette, P.L. (Eds.) (2000) Cultural Issues in End-of-Life Decision Making. Sage, Thousand Oaks. 
Scientific Research Publishing (SCIRP) is one of the largest Open Access journal publishers. It is currently publishing more than 200 open access, online, peer-reviewed journals covering a wide range of academic disciplines. SCIRP serves the worldwide academic communities and contributes to the progress and application of science with its publication.

Other selected journals from SCIRP are listed as below. Submit your manuscript to us via either submit@scirp.org or Online Submission Portal.
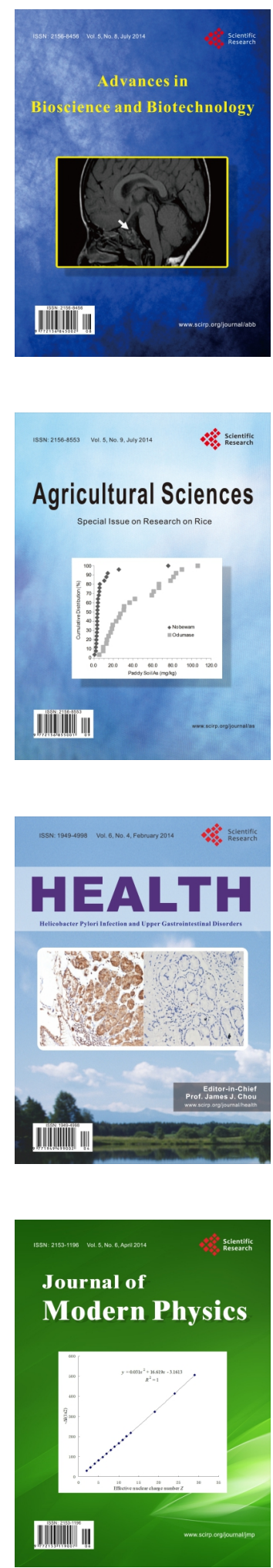
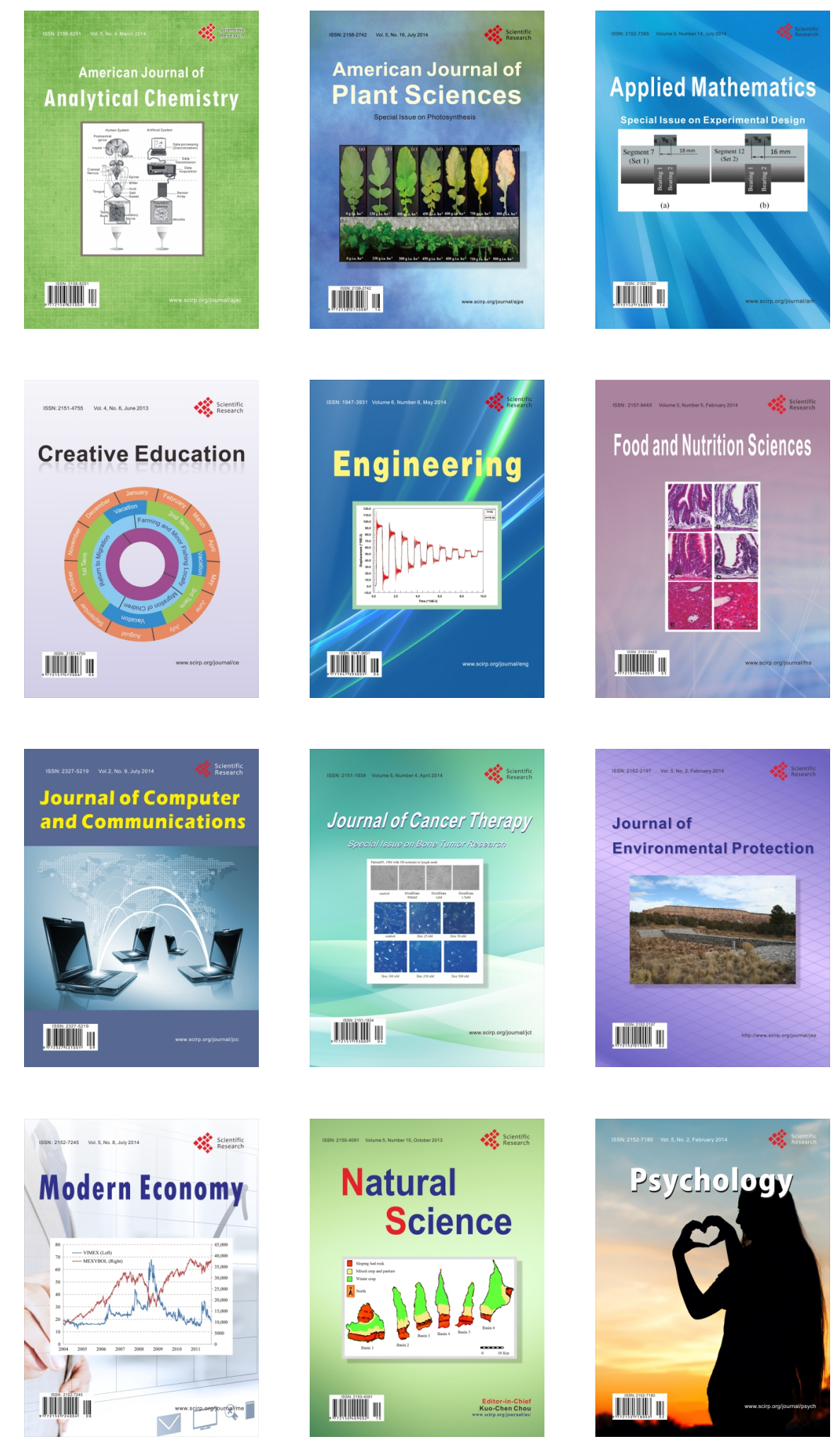